\title{
Notes on Economic Growth with Scale Effects: Is Depopulation Compatible with Growth?
}

\author{
Masao Nakagawa1, Asuka Oura2', Yoshiaki Sugimoto ${ }^{*}$ \\ ${ }^{1}$ Graduate School of Social Sciences, Hiroshima University, Higashi Hiroshima, Hiroshima, Japan \\ ${ }^{2}$ Graduate School of Economics, Osaka University, Toyonaka, Osaka, Japan \\ ${ }^{3}$ Faculty of Economics, Kansai University, Suita, Osaka, Japan \\ Email: sugimoto@kansai-u.ac.jp
}

Received 2 February 2015; accepted 18 March 2015; published 27 March 2015

Copyright ( 2015 by authors and Scientific Research Publishing Inc.

This work is licensed under the Creative Commons Attribution International License (CC BY).

http://creativecommons.org/licenses/by/4.0/

(c) (i) Open Access

\section{Abstract}

This research develops a simple theory to analyze the compatibility of depopulation and sustainable growth. By introducing the scale effect of aggregate rather than average human capital, it shows that the economy may enter a sustainable growth path with fertility recovery, keeping away from a non-Malthusian poverty trap.

\section{Keywords}

\section{Scale Effect, Depopulation, Human Capital, Growth}

\section{Introduction}

Over the last few decades, there has been a strand of theoretical literature studying the role of population in economic growth. One of its main arguments is that population expansion improves total factor productivity through various channels, including the increase in potential inventors (Kremer [1]) and R\&D activities (Romer [2], Aghion and Howitt [3]). The size of population is proposed as a key determinant for the level of output per worker, although its effect on the growth rate may vanish in the long run. ${ }^{1}$

Such theories typically build on the condition that population increases in size over time. Certainly, they can incorporate population aging as long as fertility rates are above replacement level. ${ }^{2}$ However, this restriction will

\footnotetext{
"Corresponding author.

${ }^{1}$ Jones [4] categorizes major R\&D-based growth models, including the pioneer works referred in the text, by the effectiveness of scale effects on the growth rate of per capita income. He also argues that scale effects on the level of per capita income are at work in all of those models. ${ }^{2}$ By utilizing the existing endogenous growth models, Prettner [5] investigates the effect of population aging on long-run growth performance. However, population aging is not accompanied by a population decline in his model. The model developed below makes no distinction between these two types of demographic changes.
} 
not be appropriate for some advanced economies in the future. According to the United Nations ([6], p. 11), the world between 2005 and 2010 has as many as 75 countries or areas whose total fertility levels are below replacement level. Germany, Italy, and Japan will enter the phase of population decline over the decades up to 2050 (ibid., pp. 61-62). Because depopulation would exert adverse effects on the growth process, it is not theoretically apparent whether these economies will sustain growth in the long run.

Existing studies are unsatisfactory in this respect. Although the possibility of sustainable growth against depopulation is demonstrated by Dalgaard and Kreiner [7] and Strulik [8], they treat demographic factors exogenously and thus are silent about the potential interaction between the fertility decision and the living standard. Taking this approach neglects the feedback effect of economic growth on population and fails to examine the possibility of population recovery. ${ }^{3}$

Equally important, it is questionable whether their result-steady growth in output per worker accompanied by permanent depopulation-should be interpreted as economic growth. These issues are not addressed even in a seminal work by Strulik et al. [10], which would be the most relevant to the present paper. They aim to account for the past and future dynamics of an economy in which fertility decisions and private R\&D activities are endogenous. Although the fertility rate they calibrate exhibits an upward recovery to replacement level, it is generated by an exogenous parameter change in the development process. Furthermore, they omit the possibility of stagnation resulting from depopulation by taking the entrance to a persistent growth path as historically independent. The present paper, in contrast, conducts a global dynamic analysis to present the existence of a nonMalthusian, catastrophic poverty trap, toward which population keeps shrinking and productivity goes into a stall.

Motivated by these observations, this research offers a theoretical framework for analyzing the compatibility of economic growth with depopulation. It develops a simple and tractable dynamic model of an economy that exhibits the following features. ${ }^{4}$ First, households face a quantity-quality trade-off in child rearing. Fertility decline results from a rise in education investment or, alternatively, from a decline in parental income. Second, the amount of new technology is assumed to depend on the level of aggregate rather than average human capital. This formulation, along with the quantity-quality trade-off, implies that education investment does not necessarily accelerate technological progress. Third, a rise in the technology level in turn augments skills by providing new knowledge/ideas to the young generation. ${ }^{5}$

Under such circumstances, average human capital increases over time and thus aggregate human capital exhibits faster growth than working population. Consequently the initially depopulating economy may sustain growth away from the non-Malthusian poverty trap, depending on the initial conditions on technology and human capital. The associated income growth may ultimately push the average fertility above the replacement level. The possibility of the fertility recovery is confirmed by a numerical analysis.

\section{The Model}

The economy has a one-sector, overlapping-generations structure and operates over an infinite discrete time horizon, $t=0,1,2, \cdots$. It is small in size and open to global capital markets, where the interest rate is stationary at $r>0$.

\subsection{Firms}

In perfectly competitive environments, firms generate a final good by employing physical capital and human capital (i.e., labor in efficiency units). Let $K_{t}$ and $H_{t}$, respectively, be the aggregate levels of these factor inputs in period $t$. Further, let $A_{t}>0$ be the level of labor-augmenting technology in period $t$. Their relation-

\footnotetext{
${ }^{3}$ The rise in fertility is consistent with a forecast of the United Nations, which is made by a time series model based on national experience (United Nations [9], p. 17). In “more developed” regions, including Europe, Northern America, Australia, New Zealand, and Japan, total fertility turns upward around the year 2000, approaching to replacement level (United Nations [6], p. viii and p. 12). While Strulik et al. ([10] p. 432) demonstrate fertility recovery by controlling a weight parameter for children in utility, in the model developed below, the future trend in fertility depends on the initial conditions.

${ }^{4}$ While this paper extends the growth theory developed by Galor and Weil [11], it does not take their unified approach. The focus here is on the modern era in which advanced economies have already experienced a demographic transition. Thus, the poverty trap presented in this paper does not describe the Malthusian stagnation, which results from population expansion under resource constraints.

${ }^{5}$ The scale effect on the growth rate of technology becomes negligible in the long run provided that the skill-augmenting effect is bounded above (cf. Footnote 13). The dissipation of the scale effect is in line with Jones [12], whose model is more empirically plausible in this aspect than previous R\&D-based growth theories.
} 
ship with the level of aggregate output in period $t, Y_{t}$, is expressed by a neoclassical production function $F$ such that

$$
Y_{t}=F\left(K_{t}, A_{t} H_{t}\right)=A_{t} H_{t} f\left(k_{t}\right),
$$

where $k_{t} \equiv K_{t} /\left(A_{t} H_{t}\right)$ and $f\left(k_{t}\right) \equiv F\left(k_{t}, 1\right)$. The price of the final good is normalized to unity. As a result of profit maximization by price-taking firms, $K_{t}$ and $H_{t}$ maximize the aggregate profit

$A_{t} H_{t} f\left(k_{t}\right)-r_{t} K_{t}-w_{t} H_{t}$, where $r_{t}$ and $w_{t}$ denote the rental price of physical capital and the wage rate per unit of efficiency labor, respectively, in period $t$. For simplicity, physical capital is assumed not to depreciate, so that the rental price equals the global interest rate $r$ through arbitration. Then, it follows that

$w_{t}=A_{t}\left[f(k)-f^{\prime}(k) k\right]>0$, where $k \equiv f^{\prime-1}(r)>0$.

\subsection{Households}

A new generation is born at the beginning of each period and lives for three periods. Generation $t$, born in period $t-1$, comprises a continuum of identical individuals existing on the interval $\left[0, N_{t}\right]$.

Consider the lifetime of an individual of generation $t$. In the first period, the individual engages in skill acquisition possibly with parental support. In the second period, he/she acquires $h_{t}>0$ efficiency units of labor and supplies all of them through the labor market. The earned wage income $w_{t} h_{t}$ is allocated between saving and child rearing. The adult individual raises $n_{t}$ units of identical children. Raising a child incurs $w_{t}\left(\delta+e_{t}\right)$ units of real expenditure, where $\delta>0$ and $e_{t} \geq 0$ are the basic and education cost, respectively, in terms of efficiency units of labor. ${ }^{6}$ Capital and interest are used for consumption in the post-retirement period, such that no bequests are left to the offspring. To summarize, the budget constraint is

$$
c_{t+1} \leq(1+r) w_{t}\left[h_{t}-\left(\delta+e_{t}\right) n_{t}\right] .
$$

The utility of an individual of generation $t, u_{t}$, depends not only on consumption in elderhood but also on aggregate income of his/her children. Each of these children acquires $h_{t+1}$ efficiency units of labor in period $t+1$. Taking these into account, the utility function is formulated as

$$
u_{t}=(1-\alpha) \ln c_{t+1}+\alpha \ln \left(w_{t+1} h_{t+1} n_{t}\right),
$$

where $\alpha \in(0,1)$ measures the degree of parental altruism.

The level of efficiency units of labor hinges on two factors: the levels of education and technology. Human capital is augmented by technology, which embodies knowledge and ideas, on the grounds that their availability improves the efficiency of education. This is referred to as the skill-augmenting effect. The formation of human capital is formulated as

$$
h_{t+1}=h\left(e_{t}, A_{t}\right),
$$

where $h\left(e_{t}, A_{t}\right)>0, \quad h_{e}\left(e_{t}, A_{t}\right)>0, \quad h_{A}\left(e_{t}, A_{t}\right)>0, \quad h_{e e}\left(e_{t}, A_{t}\right)<0, \quad h_{e A}\left(e_{t}, A_{t}\right)>0, \quad \lim _{e_{t} \rightarrow 0} h_{e}\left(e_{t}, A_{t}\right)=\infty$, and $\lim _{e_{t} \rightarrow \infty} h_{e}\left(e_{t}, A_{t}\right)=0 \quad \forall\left(e_{t}, A_{t}\right) \gg 0{ }^{7}$ The function $h$ exhibits diminishing marginal productivity with respect to education and is increasing in technology. The positive cross derivative indicates their complementarity in skill formation. The second-last property (i.e., the first Inada condition) precludes the existence of a corner solution at $e_{t}=0$. This preclusion would be plausible considering the present paper's focus on advanced stages of economic development.

As price takers, parents maximize their own utility by allocating resources between consumption, the quantity of children, and education for them. Substituting Equations (2) and (4) into Equation (3), the maximization problem faced by a member of generation $t$ becomes

$$
\left\{n_{t}, e_{t}\right\}=\arg \max \left\{(1-\alpha) \ln \left[h_{t}-\left(\delta+e_{t}\right) n_{t}\right]+\alpha \ln \left[h\left(e_{t}, A_{t}\right) n_{t}\right]\right\},
$$

subject to $\left(n_{t}, e_{t}\right) \geq 0$. The logarithmic form implies that $n_{t}>0$.

In terms of $n_{t}$, the objective function is strictly concave and the first-order condition yields

\footnotetext{
${ }^{6}$ Measuring the child rearing costs in labor, rather than in time, is one of the crucial deviations from the model of Galor and Weil [11]. Such an extension generates an income effect on fertility, which is the potential force of population recovery in developed stages.

${ }^{7}$ In what follows, $f_{x}(x, y)$ denotes the partial derivative of $f$ with respect to $x$. Similarly, $f_{x x}(x, y)$ and $f_{x y}(x, y)$ denote the second and cross derivatives, respectively.
} 


$$
n_{t}=\frac{\alpha h_{t}}{\delta+e_{t}}
$$

implying that $\alpha h_{t}$ is the resource allocated to child rearing. Childbirth is encouraged by a rise in parental skill (i.e., the income effect) and is discouraged by a rise in the education cost (i.e., the substitution effect).

Substitution of Equation (6) into Equation (5) reveals that the necessary and sufficient condition for an interior solution $e_{t}>0$, which is unique, is given by

$$
Q\left(e_{t}, A_{t}\right) \equiv\left(\delta+e_{t}\right) h_{e}\left(e_{t}, A_{t}\right)-h\left(e_{t}, A_{t}\right)=0,
$$

noting that $Q_{e}\left(e_{t}, A_{t}\right)<0 \quad \forall\left(e_{t}, A_{t}\right) \geq 0$. Since the existence of the solution is ensured by the Inada conditions on $h\left(e_{t}, A_{t}\right)$, the implicit function theorem establishes that the optimal education choice is given by a continuously differentiable, single-valued function

$$
e_{t}=e\left(A_{t}\right)
$$

where $e\left(A_{t}\right)>0 \forall A_{t}>0{ }^{8}$

\subsection{Aggregate Human Capital and Technological Progress}

The working population in period $t+1$ is given by $N_{t+1}=n_{t} N_{t}$. Thus, substituting Equation (8) into Equations (4) and (6), the level of aggregate human capital in period $t+1$ can be expressed as

$$
H_{t+1}=h_{t+1} N_{t+1}=\frac{\alpha h\left(e\left(A_{t}\right), A_{t}\right)}{\delta+e\left(A_{t}\right)} H_{t} \equiv \phi\left(A_{t}\right) H_{t},
$$

where $H_{0}=N_{0} h_{0}>0$ is historically given and, for any $A_{t}>0, \phi\left(A_{\tau}\right)>0$ and $\phi^{\prime}\left(A_{\tau}\right)>0$. The last property, $\phi^{\prime}\left(A_{t}\right)>0$, reflects only the direct effect of knowledge/ideas on human capital (i.e., the aforementioned skill-augmenting effect) because the effect of any marginal change in $e\left(A_{t}\right)$ on skill formation is neutralized by its opposing effect on fertility. ${ }^{9}$

As mentioned in the introduction, the present model abstracts from microeconomic foundations that account for the innovation process. Suppose that the creation of new technology is a by-product of manufacturing final output and depends on the level of aggregate rather than average human capital, on the ground that more skilled labor would come up with more ideas. Specifically, $A_{t+1}-A_{t}=B H_{t+1}$, where the parameter $B>0$ measures the degree of learning by doing. ${ }^{10}$ It follows from Equation (9) that the evolution of technology is

$$
A_{t+1}=A_{t}+B \phi\left(A_{t}\right) H_{t},
$$

where $A_{0}>0$ is historically determined.

Equations (9) and (10) constitute a two-dimensional, first-order autonomous system for $A_{t}$ and $H_{t}$. Its notable feature is a dynamic interaction between technology and aggregate human capital. The level of technology in period $t, A_{t}$, affects not only $A_{t+1}$ but also aggregate human capital in the subsequent period, $H_{t+1}$, through the skill-augmenting effect. The resulting amount of $H_{t+1}$ in turn determines $A_{t+1}$ through learning by doing.

\section{The Dynamical System}

This section explores the joint evolution of technology and aggregate human capital. As will be apparent, the initial condition on $\left(A_{0}, H_{0}\right) \gg 0$ nails down the future path of $\left(A_{t}, H_{t}\right)$, and thus, those of the other endogenous variables.

\footnotetext{
${ }^{8}$ Given the properties of $h\left(e_{t}, A_{\imath}\right)$ in Equation (4), $\lim _{e_{t} \rightarrow 0} Q\left(e_{t}, A_{\imath}\right)=\lim _{e_{t} \rightarrow 0} h_{e}\left(e_{t}, A_{\imath}\right)=\infty$ and

$\lim _{e_{t} \rightarrow \infty} Q\left(e_{t}, A_{\imath}\right)=\lim _{e_{t} \rightarrow \infty}\left[e_{t} h_{e}\left(e_{t}, A_{\imath}\right)-h\left(e_{t}, A_{\imath}\right)\right]<0$, where the inequality holds because the difference in the square brackets is negative by concavity and strictly decreasing in $e_{t}$.

${ }^{9}$ Recall that Equation (7) is the condition for $e_{t}=\arg \max \left[h\left(e_{t}, A_{i}\right) /\left(\delta+e_{t}\right)\right]$.

${ }^{10}$ This specification is viewed as a discrete counterpart of Equation (9) proposed by Jones [12], in which R\&D exhibits no externalities. Taking into account the long time interval of the OLG economy, it would be plausible to consider that $A_{t+1}-A_{\imath}$ depends on $H_{t+1}$ rather than $H_{t}$. The resulting dependence of $A_{t+1}$ on $H_{t+1}$ yields increasing returns to scale in line with Romer [13].
} 
First, as follows from Equations (9) and (10),

$$
A_{t+1}>A_{t} \text { and } H_{t}>0 \quad \forall t \geq 0 .
$$

Second, Equation (10) reveals that for any $A_{t}>0$,

$$
A_{t+1}-A_{t} \begin{cases}=0 & \text { if } H_{t}=0 \\ >0 & \text { if } H_{t}>0 .\end{cases}
$$

Third and finally, Equation (9) reveals that for any $A_{t}>0$,

$$
H_{t+1}-H_{t} \begin{cases}<0 & \text { if } A_{t}<\hat{A} \text { and } H_{t}>0 \\ =0 & \text { if } A_{t}=\hat{A} \text { or } H_{t}=0 \\ >0 & \text { if } A_{t}>\hat{A} \text { and } H_{t}>0\end{cases}
$$

where $\hat{A}>0$ is a unique value such that $\phi(\hat{A})=1$. To ensure the existence of $\hat{A}$, suppose that the growth factor of $H_{t}$ varies with $A_{t}$ so remarkably that ${ }^{11}$

$$
\lim _{A_{t} \rightarrow 0} \phi\left(A_{t}\right)<1<\lim _{A_{t} \rightarrow \infty} \phi\left(A_{t}\right) .
$$

Proposition 1 clarifies two sufficient conditions on $\left(A_{0}, H_{0}\right)$, one for convergence and the other for divergence.

Proposition 1. Under Equation (A1),

$$
\lim _{t \rightarrow \infty} A_{t}-\hat{A} \begin{cases}<0 & \text { if } A_{0}+B \Phi\left(\hat{A}^{-}\right) H_{0} \leq \hat{A}^{-} ; \\ >0 & \text { if } A_{0}+B \Phi\left(A_{0}\right) H_{0} \geq \hat{A},\end{cases}
$$

where $\left(A_{0}, H_{0}\right) \gg 0, \hat{A}^{-}(<\hat{A})$ is a fixed value, and

$$
\Phi(A) \equiv\left\{\begin{array}{lc}
\frac{\phi(A)}{1-\phi(A)}>0 & \text { if } 0<A<\hat{A} \\
0 & \text { otherwise. }
\end{array}\right.
$$

Proof. See Appendix A.

The phase diagram in Figure 1 graphically represents the properties of the dynamical system derived thus far. The upper and lower boundaries of the shaded area are the sets of $\left(A_{0}, H_{0}\right)$ for which the first and second conditions of Proposition 1 are satisfied with equality, respectively. A stationary-state equilibrium occurs at any point on the horizontal line, where $A_{t}>0$ and $H_{t}=0$. In particular, the subset $(0, \hat{A})$ is referred to as the non-Malthusian poverty trap.

Any initial pair $\left(A_{0}, H_{0}\right) \gg 0$ below the shaded area converges to one of the stationary-state equilibria in the trap. ${ }^{12}$ Note that the fall into the trap is not due to the Malthusian mechanism: the saturation of population under the resource constraint. A large population size is rather growth-promoting in the developed stages considered herein. The fall is caused by scarce initial endowments, as they restrain the aforementioned dynamic interaction between technology and aggregate human capital. As long as $\left(A_{0}, H_{0}\right)$ is given above the shaded area, $A_{t}$ eventually exceeds $\hat{A}$ and then the evolution of $H_{t}$ displays a U-shaped turnaround. ${ }^{13}$ The future path is

\footnotetext{
${ }^{11}$ As a result of calibration based on the G-7 data, Strulik et al. ([10], pp. 421 and 429) impose a similar restriction to the second inequality in Equation (A1). Unlike in the present model, however, their restriction makes the transition to the prosperous path automatic regardless of the initial conditions.

${ }^{12} \mathrm{~A}$ linear approximation reveals that $\left(A_{\imath}, H_{t}\right)$ converges to a stationary state-equilibrium $\left(A^{*}, 0\right)$, where $0<A^{*}<\hat{A}$, provided that $A^{*}=A_{0}+B \Phi\left(A^{*}\right) H_{0}$. See Appendix B for the proof.

${ }^{13}$ In the case of divergence, the growth rate of technology converges to a certain level if $\lim _{A_{\rightarrow} \rightarrow \infty} \phi\left(A_{\tau}\right) \equiv \bar{\phi}<\infty$. Since Equations (9) and (10) yield $x_{t+1}=x_{t} / \phi\left(A_{\imath}\right)+B$, where $x_{t} \equiv A_{\imath} / H_{t}$, it follows that $\lim _{t \rightarrow \infty} x_{t}=B \bar{\phi} /(\bar{\phi}-1)$ and $\lim _{t \rightarrow \infty} A_{t+1} / A_{\imath}=\bar{\phi}$. This outcome is consistent with the dissipation of scale effect asserted by Jones [12].
} 


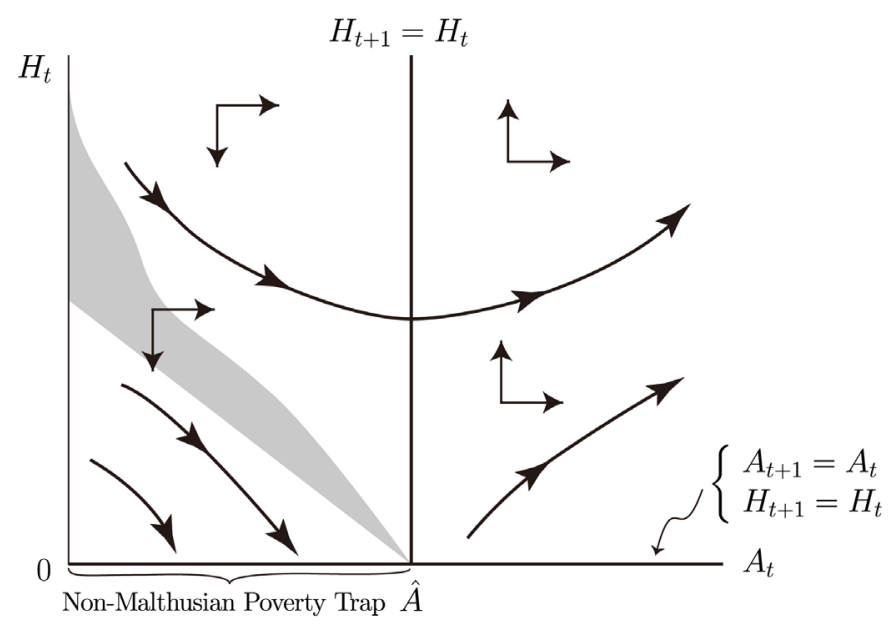

Figure 1. Global Dynamics of Technology and Human Capital. Notes: The diagram depicts the dynamical system on $\mathbb{R}_{++}^{2}$ of the $A-H$ plane. The horizontal line is a set of stationary-state equilibria. The economy may fall into the subset Non-Malthusian Poverty Trap or enter an explosive path, depending on whether the initial pair $\left(A_{0}, H_{0}\right)$ lies below or above the shaded area.

analytically ambiguous when the economy launches on the shaded area.

\section{Analyses}

\subsection{The Hurdle to Sustainable Growth}

As shown above, $\hat{A}$ is the critical value that triggers the accumulation of aggregate human capital. In this sense, $\hat{A}$ is the hurdle to prosperous, sustainable growth. Since $\phi(\hat{A})=1$ by definition, it follows from Equation (9) that $\hat{A}$ depends on two structural parameters: $\alpha$ and $\delta$, which respectively identity the degree of intergenerational altruism and the fixed cost of child rearing.

Either a decrease in $\alpha$ or an increase in $\delta$ lowers the growth factor of aggregate human capital $\phi\left(A_{\tau}\right)$ for a given $A_{t}$. The resulting rise in $\hat{A}$ makes it more difficult for the economy to enter on the explosive path. In light of the first condition of Equation (13), a rise in $\hat{A}$ expands the domain of $\left(A_{0}, H_{0}\right)$ on which the economy falls into the non-Malthusian poverty trap in Figure 1. Even if the economy is initially on the explosive path, its growth process may be averted by a permanent change in those parameters. For instance, the degree of parental altruism might be affected by the growth of nuclear families and a shift in social norms through international exchanges. The fixed cost of child rearing would be higher as a result of natural disasters and deterioration in the quality of public services.

\subsection{Growth and Depopulation}

This subsection investigates population dynamics underlying the growth process. In line with Equation (17) in Strulik et al. [10], aggregate human capital $H_{t}$ is decomposed into average human capital $h_{t}$ and working population $N_{t}$ when expressing the growth factor:

$$
\frac{H_{t+1}}{H_{t}}=\frac{h_{t+1}}{h_{t}} n_{t},
$$

where $h_{t}=H_{t} / N_{t}$ and $n_{t}=N_{t+1} / N_{t}$. Noting Equation (10), we can see that at least either $h_{t}$ or $N_{t}$ needs to grow in the long run to sustain productivity growth at a positive rate.

In view of Equations (4) and (8), the dynamic behavior of $h_{t+1}$ depends on how education investment reacts to technological progress. The analysis below considers a strong complementarity between education and technology in skill formation. Formally, 


$$
h\left(e_{t}, A_{t}\right) h_{e A}\left(e_{t}, A_{t}\right)>h_{e}\left(e_{t}, A_{t}\right) h_{A}\left(e_{t}, A_{t}\right) \quad \forall\left(e_{t}, A_{t}\right) \gg 0 .
$$

The complementary relationship in Equation (A2) generates a stimulative effect of technological progress on education investment; that is to say, ${ }^{14}$

$$
e^{\prime}\left(A_{t}\right)>0 \quad \forall A_{t}>0 .
$$

These results, along with Equation (11) showing monotonic technological progress, reveal that $h_{t+1} / h_{t}>1$ $\forall t \geq 1$ and, therefore,

$$
\frac{H_{t+1}}{H_{t}}>n_{t} \quad \forall t \geq 1
$$

Thus, working population decreases as long as aggregate human capital decreases, or equivalently, as long as $A_{t}$ is below $\hat{A}$ in Figure $1 .{ }^{15}$ On the other hand, it does not necessarily begin growing at the onset of the accumulation of aggregate human capital, which occurs when $A_{t}$ exceeds $\hat{A}$. These indicate that initial depopulation does not necessarily block the way to sustainable growth.

While Equation (16) indicates the possibility of initial depopulation on an explosive path, it is not apparent whether or not such a demographic trend continues. One certain fact from Equation (14) is that the onset of population expansion is inevitable if average human capital $h_{t}$ converges toward a certain level on the path. ${ }^{16}$ This case is brought about by a bounded production function of human capital satisfying Equation (A1). In the long-run, depopulation is compatible with productivity growth only if average human capital keeps increasing.

\subsection{The Dynamic Trend in Fertility}

As mentioned earlier, it is generally not clear whether or not $n_{t}$ reaches the replacement level, and it is analytically difficult to characterize its dynamic behavior. The difficulty stems from two counteracting effects of technological change on fertility. In light of Equations (4), (6), and (8),

$$
n_{t}=\frac{\alpha h\left(e\left(A_{t-1}\right), A_{t-1}\right)}{\delta+e\left(A_{t}\right)} .
$$

Given Equation (15), a change in $A_{t-1}$ enhances $h_{t}$ both directly and indirectly, generating the income effect on $n_{t}$. On the other hand, an increase in $A_{t}$ shifts resources from the quantity to the quality of children (i.e., the substitution effect). These forces would make the dynamic trend in fertility, analytically ambiguous.

A quantitative prediction of fertility is depicted in Figure 2, where one time period equals 30 years. The observed recovery to replacement level occurs under the following conditions. First, the production function of human capital is specified as

$$
h\left(e_{t}, A_{t}\right)=e_{t}^{\gamma} A_{t}^{1-\gamma}+\theta,
$$

where $\gamma \in(0,1)$ and $\theta>0$ is interpreted as the level of basic skills any individual acquires in adulthood. Note that the function exhibits the property in Equation (A2): strong complementarity between education and technology in skill formation. ${ }^{17}$ Second, initial values of population and human capital are normalized to one, that is, $N_{0}=1$ and $h_{0}=1$. Third, the structural parameters and initial condition on technology are such that

\footnotetext{
${ }^{14}$ Applying the implicit function theorem to Equation (7), $e^{\prime}\left(A_{\imath}\right)=\left[-Q_{A}\left(e_{t}, A_{t}\right)\right] / Q_{e}\left(e_{t}, A_{t}\right)$, where $e_{t}=e\left(A_{\imath}\right)$. Equations (7) and (A2) imply that the numerator is negative, whereas $Q_{e}\left(e_{t}, A_{\imath}\right)<0 \quad \forall\left(e_{t}, A_{i}\right) \gg 0$.

${ }^{15}$ Negative population growth with low technology appears to be inconsistent with the historical experience of most economies, whose population has been expanding (cf. Maddison [14], p. 241). As mentioned in the introduction, however, the focus here is on the contemporary period in which advanced economies begin aging, and encompassing the demographic patterns over the past millennia is beyond the scope of the present research. For this reason, the initial technology level $A_{0}$ is considered to be above a certain level, even though $A_{0}$ may be smaller than $\hat{A}$.

${ }^{16}$ Strulik et al. [10] preclude such a case by setting the productivity parameter for education investment so large that $\lim t_{t \rightarrow \infty} h_{t+1} / h_{t}>1$ (cf. Footnote 11). This condition is crucial, but not sufficient, for the accumulation of aggregate human capital against depopulation in the long run.

${ }^{17}$ Equation (18) yields $h\left(e_{t}, A_{\imath}\right) h_{e A}\left(e_{t}, A_{\imath}\right)-h_{e}\left(e_{t}, A_{\imath}\right) h_{A}\left(e_{t}, A_{\imath}\right)=\theta \gamma(1-\gamma) e_{t}^{\gamma-1} A_{\tau}^{-\gamma}$.
} 


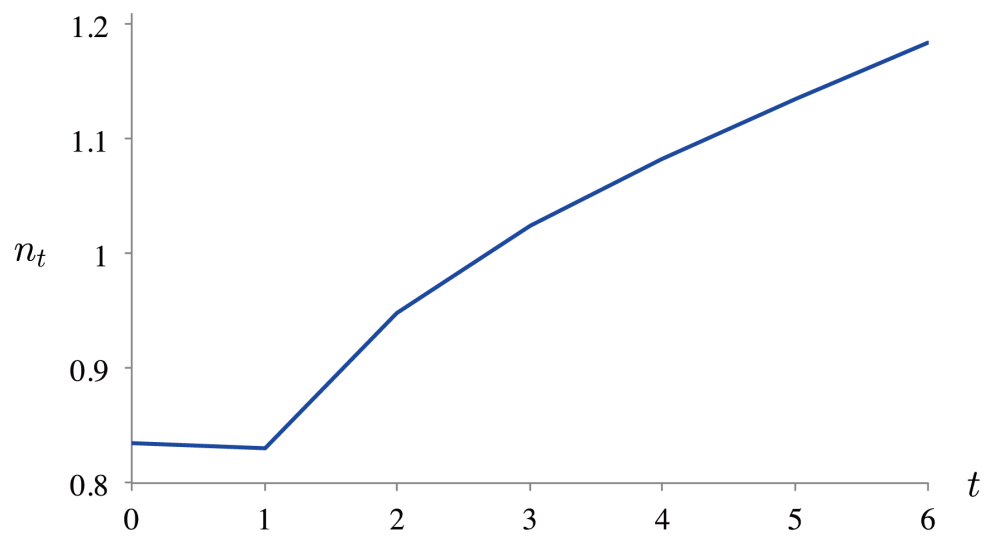

Figure 2. A Quantitative Prediction of Fertility.

$\alpha=0.146, \delta=0.0868, B=935, \gamma=0.777, \theta=0.390$ and $A_{0}=1050$, which are calibrated to match the empirical evidence in developed countries. ${ }^{18}$

Under these circumstances, the initial level of average fertility is $n_{0}=0.835$, which is consistent with the experience of more developed regions from 1990 to 1995 (United Nations [6], p. 12). ${ }^{19}$ Per worker output $A_{t} h_{t}$ increases twofold in 30 years, implying an annual growth rate of about $2.34 \%$.

\section{Concluding Remarks}

The growth theory developed above has demonstrated that in the presence of a scale effect of human capital, the initial conditions on technology, population, and human capital determine whether an economy undergoing depopulation enters a steady-growth path, along which population growth may ultimately turn positive. The possibility of falling into the poverty trap is explained by initial depopulation, which depresses the scale effect on productivity growth. In addition to the main result, a permanent decline in parental altruism or in the fixed cost of child rearing raises the hurdle to sustainable growth and may thereby divert the economy from the prosperous path.

Without taking a unified-approach, the present paper focuses on the developed economy whose initial fertility rate is below replacement level. As such, the unsolved questions are how the initial conditions are determined and why they are different among advanced countries. In order to answer them, it is necessary to extend the model and consider the process of fertility decline from a longer-term perspective. This theme is left for future research.

\section{Acknowledgements}

The authors are grateful to Koichi Futagami, Ken Tabata, and the participants of the 8th Conference of Macroeconomics for Young Professionals (2014, Osaka), the 2014 Asian Meeting of the Econometric Society, and the 2014 Australia Meeting of the Econometric Society, for their useful comments and encouragement. This research benefited from a Grant-in-Aid for JSPS Fellows (26-3695).

\section{References}

[1] Kremer, M. (1993) Population Growth and Technological Change: One Million B.C. to 1990. Quarterly Journal of Economics, 108, 681-716. http://dx.doi.org/10.2307/2118405

[2] Romer, P.M. (1990) Endogenous Technological Change. Journal of Political Economy, 98, S71-S102. http://dx.doi.org/10.1086/261725

[3] Aghion, P. and Howitt, P. (1992) A Model of Growth through Creative Destruction. Econometrica, 60, 323-351.

\footnotetext{
${ }^{18}$ In light of Haveman and Wolf ([15], Table 1) and de la Croix and Doepke ([16], p. 1099), we choose the US as a representative developed country and assume that parents initially spend $7.25 \%$ of their potential income on the fixed cost and $7.3 \%$ on child education.

${ }^{19}$ The total fertility rate reported in the reference is 1.67 . Note that $n_{t}$ should be half of the total fertility rate in the real world because all adult individuals give birth in this economy.
} 
http://dx.doi.org/10.2307/2951599

[4] Jones, C.I. (1999) Growth: With or Without Scale Effects? American Economic Review: Papers and Proceedings, 89, 139-144. http://dx.doi.org/10.1257/aer.89.2.139

[5] Prettner, K. (2013) Population Aging and Endogenous Economic Growth. Journal of Population Economics, 26, 811834. http://dx.doi.org/10.1007/s00148-012-0441-9

[6] Department of Economic and Social Affairs, Population Division, United Nations (2013) World Population Prospects: The 2012 Revision, Volume I: Comprehensive Tables ST/ESA/SER.A/336. http://esa.un.org/wpp/Documentation/pdf/WPP2012_Volume-I_Comprehensive-Tables.pdf

[7] Dalgaard, C.J. and Kreiner, C.T. (2001) Is Declining Productivity Inevitable? Journal of Economic Growth, 6, 187-203. http://dx.doi.org/10.1023/A:1011343715594

[8] Strulik, H. (2005) The Role of Human Capital and Population Growth in R \& D-Based Models of Economic Growth. Review of International Economics, 13, 129-145. http://dx.doi.org/10.1111/j.1467-9396.2005.00495.x

[9] Department of Economic and Social Affairs, Population Division, United Nations (2014) World Population Prospects: The 2012 Revision, Methodology of the United Nations Population Estimates and Projections. Working Paper No. ESA/P/WP.235. http://esa.un.org/wpp/Documentation/pdf/WPP2012_Methodology.pdf

[10] Strulik, H., Prettner, K. and Prskawetz, A. (2013) The Past and Future of Knowledge-Based Growth. Journal of Economic Growth, 18, 411-437. http://dx.doi.org/10.1007/s10887-013-9098-9

[11] Galor, O. and Weil, D.N. (2000) Population, Technology, and Growth: From Malthusian Stagnation to the Demographic Transition and Beyond. American Economic Review, 90, 806-828. http://dx.doi.org/10.1257/aer.90.4.806

[12] Jones, C.I. (1995) R \& D-Based Models of Economic Growth. Journal of Political Economy, 103, 759-784. http://dx.doi.org/10.1086/262002

[13] Romer, P.M. (1986) Increasing Returns and Long-Run Growth. Journal of Political Economy, 94, 1002-1037. http://dx.doi.org/10.1086/261420

[14] Maddison, A. (2006) The World Economy, Volume 1: A Millennial Perspective. The OECD Development Centre, Paris (Originally Published in 2001). http://dx.doi.org/10.1787/9789264022621-en

[15] Haveman, R. and Wolfe, B. (1995) The Determinants of Children's Attainments: Findings and Review of Methods. Journal of Economic Literature, 33, 1829-1878.

[16] de la Croix, D. and Doepke, M. (2003) Inequality and Growth: Why Differential Fertility Matters. American Economic Review, 93, 1091-1113. http://dx.doi.org/10.1257/000282803769206214 


\section{Appendix}

\section{A. Proof of Proposition 1}

The properties of $\phi$ in Equations (9) and (A1) ensure the existence of a unique value $\hat{A}$ such that $\phi(\hat{A})=1$. Since $A_{t}$ is the stock of inventions up to period $t$, Equations (9)-(11) reveal that for $t \geq 1$,

$$
A_{t}=A_{0}+\sum_{s=1}^{t}\left(A_{s}-A_{s-1}\right)=A_{0}+B H_{0} \sum_{s=1}^{t} \prod_{j=0}^{s-1} \phi\left(A_{j}\right),
$$

where $0<A_{0}<A_{1}<\cdots<A_{t}$ and $H_{0}>0$. Then, it follows that if $A_{t-1} \leq \hat{A}^{-}(<\hat{A})$ in period $t-1 \geq 0$, then $A_{t}<A_{0}+B H_{0} \phi\left(\hat{A}^{-}\right) /\left[1-\phi\left(\hat{A}^{-}\right)\right]$, where $0<\phi\left(\hat{A}^{-}\right)<1$. Thus, given the first condition in Equation (13), $A_{0}<\hat{A}^{-}$and then $A_{t}<\hat{A}^{-} \quad \forall t \geq 0$. This implies that $\lim _{t \rightarrow \infty} A_{t}<\hat{A}$; otherwise, $A_{t} \geq \hat{A}$ occurs in a period $t$. Under the second condition in Equation (13), $\lim _{t \rightarrow \infty} A_{t}>\hat{A}$ because $A_{t}>A_{0}+B H_{0} \sum_{s=1}^{t}\left[\phi\left(A_{0}\right)\right]^{s} \quad \forall t \geq 2$ from Equation (A.1).

\section{B. Local Analysis of the Poverty Trap}

From Equations (9) and (10),

$$
\begin{aligned}
& A_{t}=A_{t-1}+B \phi\left(A_{t-1}\right) H_{t-1} ; \\
& H_{t}=\phi\left(A_{t-1}\right) H_{t-1},
\end{aligned}
$$

where $\left(A_{0}, H_{0}\right) \gg 0$. This dynamical system has a steady-state equilibrium $\left(A^{*}, 0\right)$, where $0<A^{*}<\hat{A}$. A linear approximation in the neighborhood yields

$$
\left(\begin{array}{c}
A_{t}-A^{*} \\
H_{t}
\end{array}\right)=\left(\begin{array}{cc}
1 & B \phi^{*} \\
0 & \phi^{*}
\end{array}\right)\left(\begin{array}{c}
A_{t-1}-A^{*} \\
H_{t-1}
\end{array}\right)=\left(\begin{array}{cc}
1 & B \phi^{*} \\
0 & \phi^{*}
\end{array}\right)^{t}\left(\begin{array}{c}
A_{0}-A^{*} \\
H_{0}
\end{array}\right),
$$

where $\phi^{*} \equiv \phi\left(A^{*}\right) \in(0,1)$ and

$$
\left(\begin{array}{cc}
1 & B \phi^{*} \\
0 & \phi^{*}
\end{array}\right)^{t}=\left(\begin{array}{cc}
1 & B \frac{\phi^{*}\left(1-\phi^{* t}\right)}{1-\phi^{*}} \\
0 & \phi^{* t}
\end{array}\right) .
$$

Thus, it follows that $H_{t}=\phi^{* t} H_{0}$ and

$$
A_{t}=A_{0}+B \frac{\phi^{*}\left(1-\phi^{* t}\right)}{1-\phi^{*}} H_{0}
$$

Now one finds that $\lim _{t \rightarrow \infty} H_{t}=0$ and

$$
\lim _{t \rightarrow \infty} A_{t}=A_{0}+B \Phi\left(A^{*}\right) H_{0},
$$

where the function $\Phi$ is from Equation (13). Therefore, $\left(A_{t}, H_{t}\right)$ converges to $\left(A^{*}, 0\right)$ provided that $A^{*}=A_{0}+B \Phi\left(A^{*}\right) H_{0}$. 